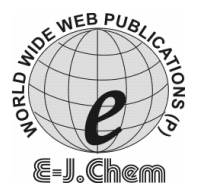

http://www.e-journals.net
CODEN ECJHAO

E-Journal of Chemistry

Vol. 3, No.1, pp 60-64, January 2006

\title{
RP-HPLC Determination of Raloxifene in Pharmaceuticl Tablets
}

\author{
P. VENKATA REDDY, B. SUDHA RANI, \\ G. SRINU BABU and J. V. L. N. SESHAGIRI RAO* \\ College of Pharmaceutical Sciences, \\ Andhra University. \\ Visakhapatnam-530003, India.
}

Received 1 November 2005; Accepted 23 January 2006

\begin{abstract}
A reverse phase HPLC method is developed for the determination of Raloxifene in pharmaceutical dosage forms. Chromatography was carried out on an inertsil C18 column using a mixture of acetonitrile and phosphate buffer (30:70 $\mathrm{v} / \mathrm{v})$ as the mobile phase at a flow rate of $1 \mathrm{~mL} / \mathrm{min}$. Detection was carried out at $290 \mathrm{~nm}$.The retention time of the drug was $10.609 \mathrm{~min}$. The method produced linear responses in the concentration range of $0.5-200 \mu \mathrm{g} / \mathrm{mL}$ of Raloxifene. The method was found to be applicable for determination of the drug in tablets.
\end{abstract}

Key words:. Raloxifene, Estimation, Tablets, RP-HPLC.

\section{Introduction}

Raloxifene is a polyhydroxylated non-steroidal compound with a benzothiophene core. It is an estrogenagonist in bone, where it exerts an antiresorptive effect. The results of several large clinical trials have shown that raloxifene reduces the rate of bone loss at both distal sites and in the spinal column and may increase bone mass at certain sites ${ }^{1}$. The drug has beneficial actions on lipoprotein metabolism, reducing both total cholesterol and LDL; however, HDL is not increased unlike with estrogen-replacement therapy. Pre-clinical studies indicate that raloxifene has an antiproliferactive effect on estrogen receptor (ER)positive breast tumors and on the proliferation of ER-positive breast cancer cell lines and significantly reduces the risk of ER-positive but not ER-negative breast cancer ${ }^{2}$. Adverse effects include deep vein thrombosis, pulmonary embolism and legcramps ${ }^{3}$. Raloxifene is adsorbed rapidly after oral administration and has an absolute bioavailability of about $2 \%$. The drug has a half-life of about $28 \mathrm{~h}$ and is eliminated primarily in the faeces after hepatic glucuronidation ${ }^{3}$. Mono- and di-oxygenated metabolites of raloxifene have been recognized 
by microsomal incubation and receptor binding using fast LC/fast scanning MS ${ }^{4}$. There are very few methods described in the literature for the determination of raloxifene. All of them use high-performance liquid chromatography (HPLC). The drug has been determined in human plasma using the LC/MS/MS technique ${ }^{5}$. Reverse phase HPLC with UV detection has been proposed for quantifying raloxifene hydrochloride ${ }^{6,7}$. Capillary electrophoresis (CE) is gaining widespread acceptance as a standard analytical technique in pharmaceutical analysis owing to its many advantageous features, such as extremely high efficiency, high resolution, rapid analysis and small consumption of sample and reagents. CE has been employed in the determination of a variety of compounds including, pharmaceuticals, proteins, polymers and food constituents ${ }^{8,9}$.

Now the authors report a simple, reliable and reproducible RP-HPLC method which was duly validated by statistical parameters precision, accuracy and recovery. The method has been satisfactorily applied to the determination of raloxifene in harmaceutical preparations.

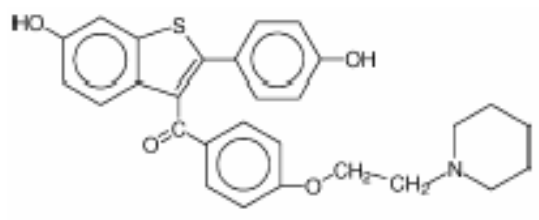

Structure of Raloxifene

\section{Experimental}

\section{Chemicals and Solvents}

HPLC grade acetonitrile (Qualigens), potassium dihydrogen phosphate and ortho phosphoric acid (AR grade, Qualigens) were used for preparing the buffer. Pure samples of Raloxifene (Torrent) and commercial samples of tablets containing the drug namely Esserm (Torrent), Fiona (Reddy's), Ralista (Cipla) were employed in the study.

\section{Chromatographic Conditions}

A gradient HPLC system (Waters) with Waters 1525 binary HPLC pump, a RP C18 column (150 x $4.6 \mathrm{~mm}$ I.D, W03281S024, particle size $5 \mu \mathrm{m}$ ), a $2487 \mathrm{UV}$ dual absorbance detector was employed. The system was run by Waters breeze software. A freshly prepared 30:70 v/v mixture of acetonitrile and phophate buffer $(2.0 \mathrm{pH})$ was used as the mobile phase. Buffer was prepared by dissolving $20.41 \mathrm{~g}$ of potassium dihydrogen phosphate in 11 of water and adjusting the $\mathrm{pH}$ to 2.0 with water. Both acetonitrile and phosphate buffer were filtered through a $0.45 \mu \mathrm{m}$ membrane filter and sonicated before use. The flow rate of the mobile phase was maintained at $1 \mathrm{~mL} / \mathrm{min}$. The detection was carried out at $280 \mathrm{~nm}$.

\section{Estimation of Raloxifene}

About $50 \mathrm{mg}$ of Raloxifene was weighed accurately and transferred into a $50 \mathrm{~mL}$ volumetric flask and dissolved in $25 \mathrm{~mL}$ methanol. The solution was sonicated for $15 \mathrm{~min}$ and then the volume was made up with a further quantity of the methanol to get a $1 \mathrm{mg} / \mathrm{mL}$ solution. Subsequent dilutions of this solution ranging from $0.5-50 \mu \mathrm{g} / \mathrm{mL}$ were made in $10 \mathrm{~mL}$ volumetric flasks with the mobile phase. $20 \mu \mathrm{L}$ of the solution was injected each time into the column, at a flow rate of $1 \mathrm{~mL} / \mathrm{min}$. Each of the dilutions was injected 5 times into the 
column and the corresponding chromatograms were obtained. From these chromatograms, the retention times and the areas under the peaks of the drug were noted. The regression equation of the drug concentrations was computed. This equation was later used to estimate the amount of Raloxifene in pharmaceutical dosage forms. To check the intra-day an interday variation of the method, solutions containing $10 \mathrm{and} 20 \mu \mathrm{g} / \mathrm{mL}$ of Raloxifene were subjected to the proposed HPLC method of analysis and the recoveries were noted.

\section{Estimation of the Drug in Tablet Dosage Forms}

Three commercial brands of tablets Esserm (Torrent), Fiona (Reddy's), Ralista (Cipla) were chosen for testing the suitability of the proposed method to estimate Raloxifene in tablet formulations. For this, twenty tablets were weighed and powdered. An accurately weighed portion of this powder equivalent to $50 \mathrm{mg}$ of Raloxifene was transferred into a $50 \mathrm{~mL}$ volumetric flask containing $25 \mathrm{~mL}$ methanol. The contents were allowed to stand for half an hour with intermittent sonication to ensure complete solubility of the drug and then filtered through a $0.45 \mu \mathrm{m}$ membrane filter. Appropriate volume of this filtrate equivalent to 10 $\mu \mathrm{g} / \mathrm{mL}$ of the drug was taken in a $10 \mathrm{~mL}$ volumetric flask. The contents of the flask were made up to the volume with the mobile phase and mixed well. $20 \mu \mathrm{L}$ of the solution was then injected into the column. The mean peak area of the drug of five such determinations was calculated and the drug content in the tablets was quantified using the regression equation obtained for the pure sample.

\section{Results and Discussion}

The present study was aimed at developing a sensitive, precise and accurate HPLC method for the analysis of Raloxifene in pharmaceutical dosage forms. For this, a binary mixture of acetonitrile and phophate buffer $(30: 70 \mathrm{v} / \mathrm{v})$ portion was found to be the most suitable mobile phase as the chromatographic peaks obtained with this system were better defined and resolved and all almost free from tailing. Under the above mentioned conditions, the retention time obtained for Raloxifene was $10.609 \mathrm{~min}$. A model chromatogram was shown in Figure 1. A good linear relationship $(r=0.9997)$ was observed between the concentration of Raloxifene and respective peak areas. The regression curve was constructed by linear regression fitting and its mathematical expression was $y=387136.2$ - $5989.23 x$ ( where ' $y$ ' is peak area and ' $x$ ' is the concentration of Raloxifene). The regression characters were given in Table 2. The intra-day inter-day drug variation studies by the proposed method showed low coefficient of variation, as shown in Table 3.The drug content in the tablets was quantified using the proposed method of analysis. The mean amount of Raloxifene obtained in tablet dosage forms is shown in Table 4. This reveals that the method is quite precise. The absence of additional peaks in the chromatogram indicated non interference of the common excipients used in the tablets.

It can be concluded that the proposed HPLC method is sensitive and reproducible for the analysis of Raloxifene in pharmaceutical dosage forms in a short analysis time. The method was duly validated by evaluation of the required parameters.

Table 1. Calibration of the Proposed Method

\begin{tabular}{cc}
\hline Concentration of Raloxifene $(\mu \mathrm{g} / \mathrm{mL})$ & Peak area \\
\hline 10 & 384111.8 \\
20 & 768292.0 \\
30 & 1123345 \\
40 & 1564876 \\
50 & 1930484 \\
\hline
\end{tabular}


Table-2. Regression Characters Of The Proposed HPLC Method

\begin{tabular}{lc}
\hline \multicolumn{1}{c}{ Parameters } & Value \\
\hline Standard deviation on slope (Sb) & 473.92 \\
Standard deviation on intercept (Sa) & 14348.8 \\
Standard error of estimation (Se) & 19825.8 \\
Relative standard deviation (\%) & 0.48450 \\
\% range of error at 95\% confidence limit & 0.40510 \\
\% range of error at 99\% confidence limit & 0.59940 \\
Slope (a) & 387136.2 \\
Intercept (b) & -5989.23 \\
Correlation coefficient (r) & 0.99970 \\
\hline
\end{tabular}

Table-3. Intra and Inter Day Precision of the Proposed Method

\begin{tabular}{ccccc}
\hline \multirow{2}{*}{$\begin{array}{c}\text { Concentration of } \\
\text { Raloxifene }(\mu \mathrm{g} / \mathrm{mL})\end{array}$} & \multicolumn{2}{c}{ Observed concentration of Raloxifene $(\mu \mathrm{g} / \mathrm{mL})$} \\
\cline { 2 - 5 } & \multicolumn{3}{c}{ Intra-day } & \multicolumn{3}{c}{ Inter-day } \\
& Mean $(\mathrm{n}=5)$ & $\operatorname{RSD}(\%)$ & Mean $(\mathrm{n}=5)$ & $\operatorname{RSD}(\%)$ \\
\hline 10 & 9.96 & 1.04 & 10.02 & 0.89 \\
20 & 20.02 & 0.98 & 24.95 & 0.94 \\
\hline
\end{tabular}

Table-4. Assay of Raloxifene in Tablet Dosage Forms

\begin{tabular}{lccc}
\hline $\begin{array}{l}\text { Brand name } \\
\text { Of theTablet } \\
(\mathrm{n}=5)\end{array}$ & $\begin{array}{c}\text { Labelled amount } \\
\text { of drug }(\mathrm{mg})\end{array}$ & $\begin{array}{c}\text { Mean }( \pm \text { S.d) amount found } \\
\text { by the proposed method }(\mathrm{n}=5)\end{array}$ & $\begin{array}{c}\text { Mean \% } \\
\text { labeled amount }\end{array}$ \\
\hline Esserm & 10 & $9.98 \pm 0.34$ & 99.8 \\
Fiona & 10 & $9.96 \pm 0.54$ & 99.6 \\
Ralista & 10 & $10.04 \pm 0.67$ & 100.4 \\
\hline
\end{tabular}

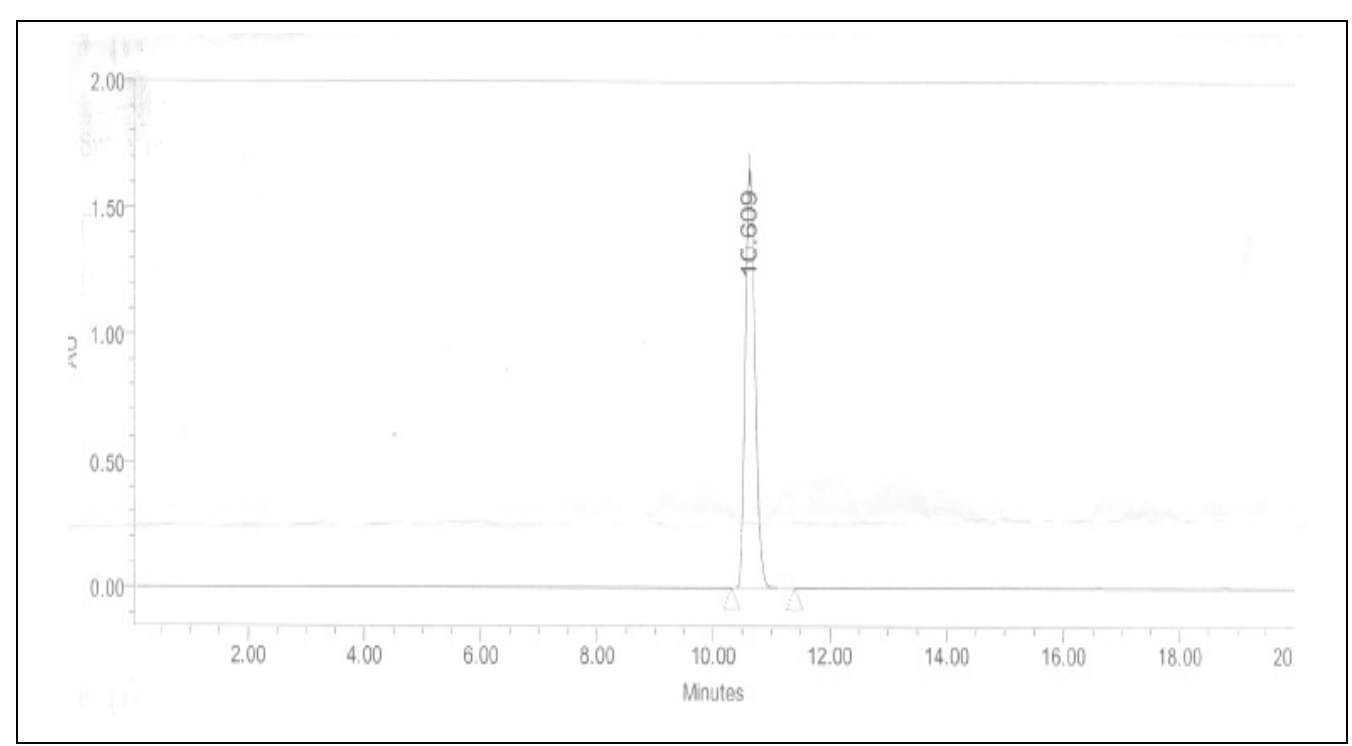

Figure 1. A model chromatogram of Raloxifene 


\section{References}

1 Delmas P , Bjarnason N H, Mitlak B H, Ravoux A C, Shah A S, Huster W J, Draper M and Christiansen C N, Engl. J. Med.1997, 337, 1641-1647.

2 Hol T, Cox M B, Bryant H U and Draper M W J, Womens Health.1997, 6, 523.

3 Hardman J G and Limbird L E, (Eds.), Goodman and Gilman's, The Pharmacological , Basis of Therapeutics, 10th ed., McGraw-Hill, New York, 2001.

4 Lim H K, Stellingweif S, Sisenwine S and Chan K W, J.Chromatogr. A 1999, 831, 227-241.

$5 \quad$ Zweigenbaum J and Henion J, Anal. Chem. 2000, 72, 2446-2454.

$6 \quad$ Nandini P, Jayant W P, Indian Drugs, 2001, 38, 591-592.

7 Wang Q, Zhang H M, Yu Z G and Shenyang Yaoke Daxue Xuebao. 2002, 19, 105.

8 Lunte S M, Radzik D M, Pharmaceutical and Biomedical Applications of Capillary Electrophoresis, Elsevier, Oxford, 1996.

9 Shintani H and Polonsky J, Handbook of Capillary Electrophoresis Applications, Chapman \& Hall, London, 1997. 


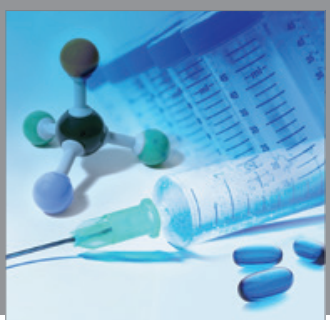

International Journal of

Medicinal Chemistry

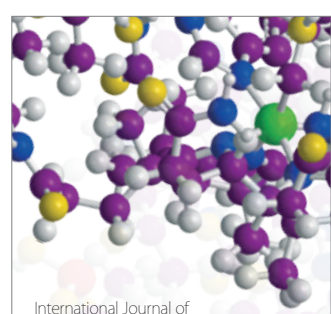

Carbohydrate Chemistry

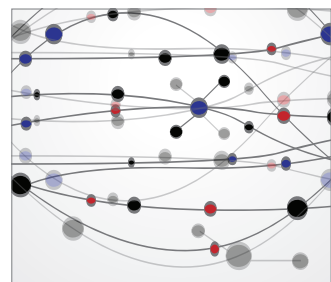

The Scientific World Journal
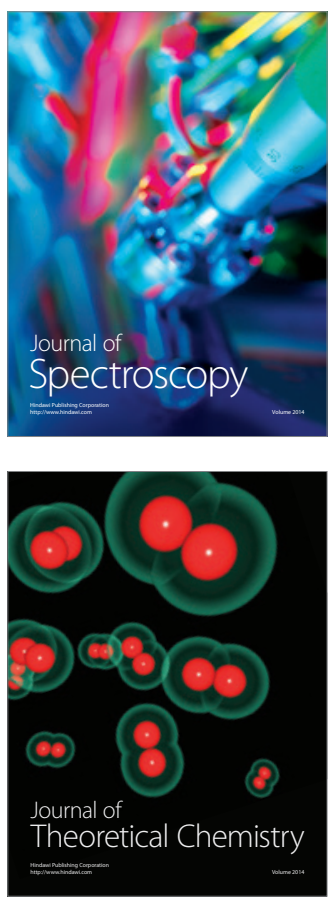
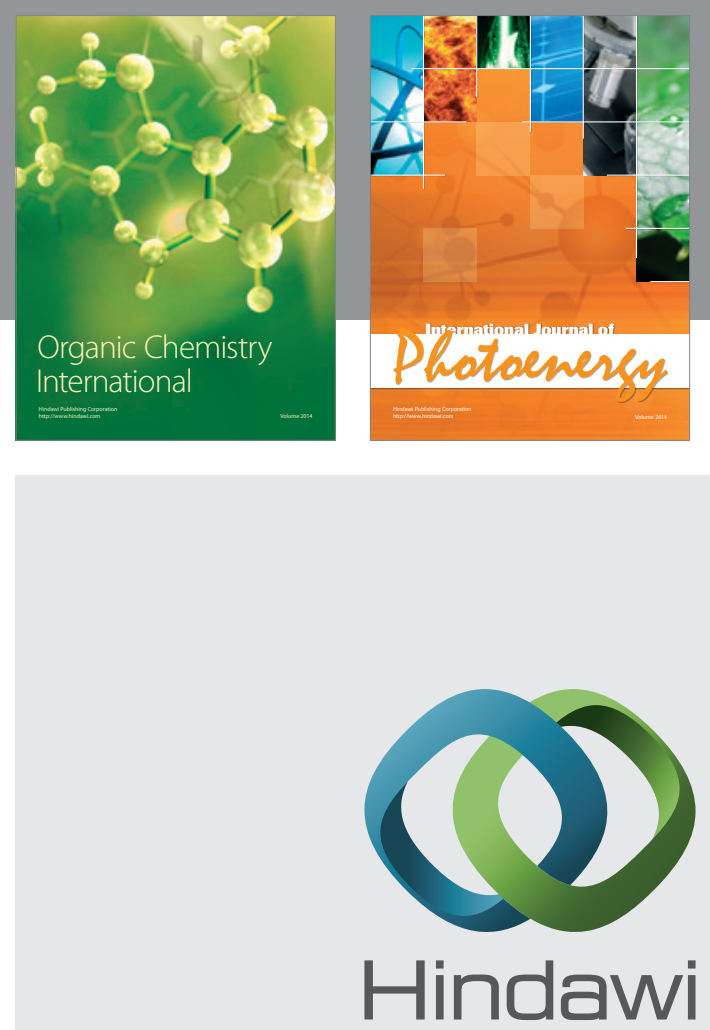

Submit your manuscripts at

http://www.hindawi.com
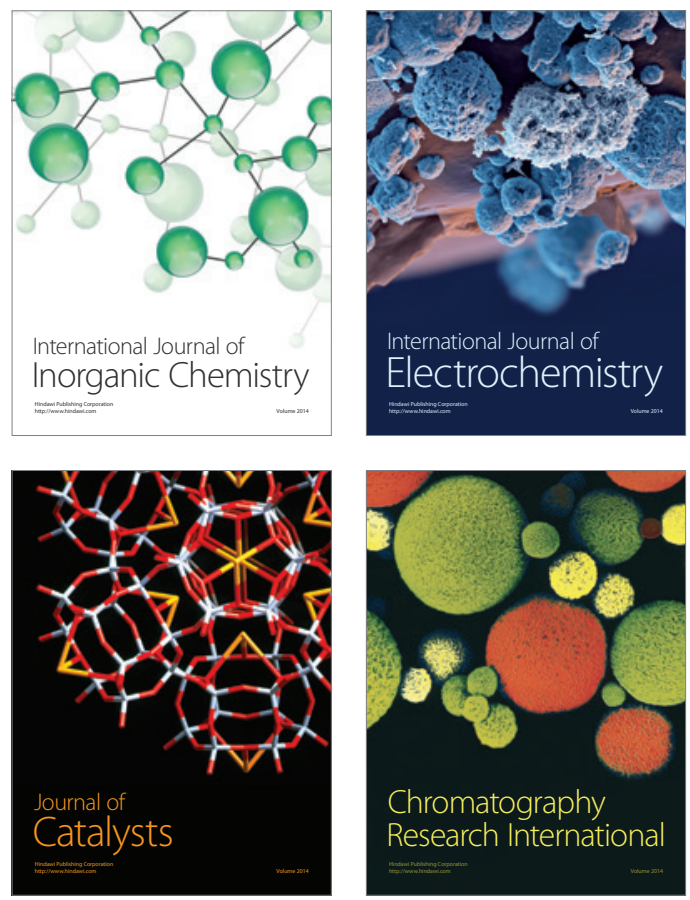
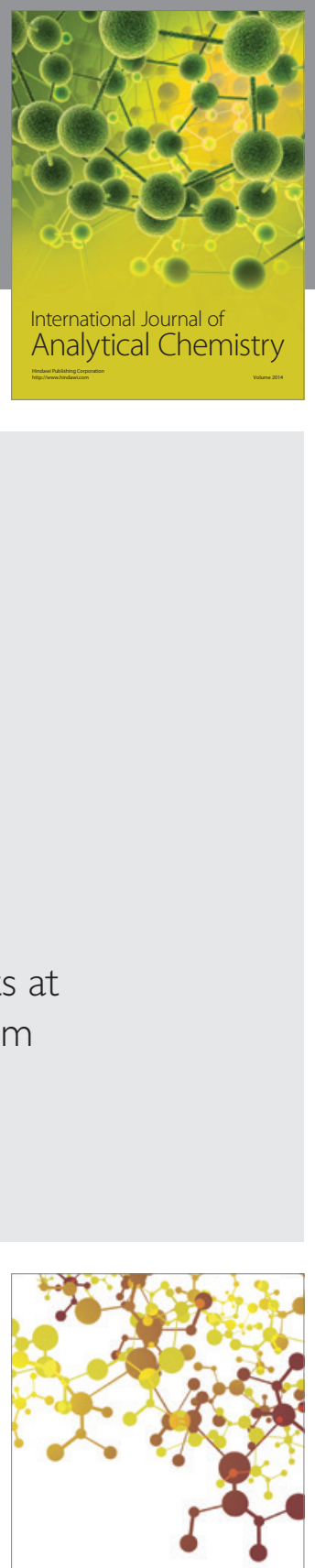

Journal of

Applied Chemistry
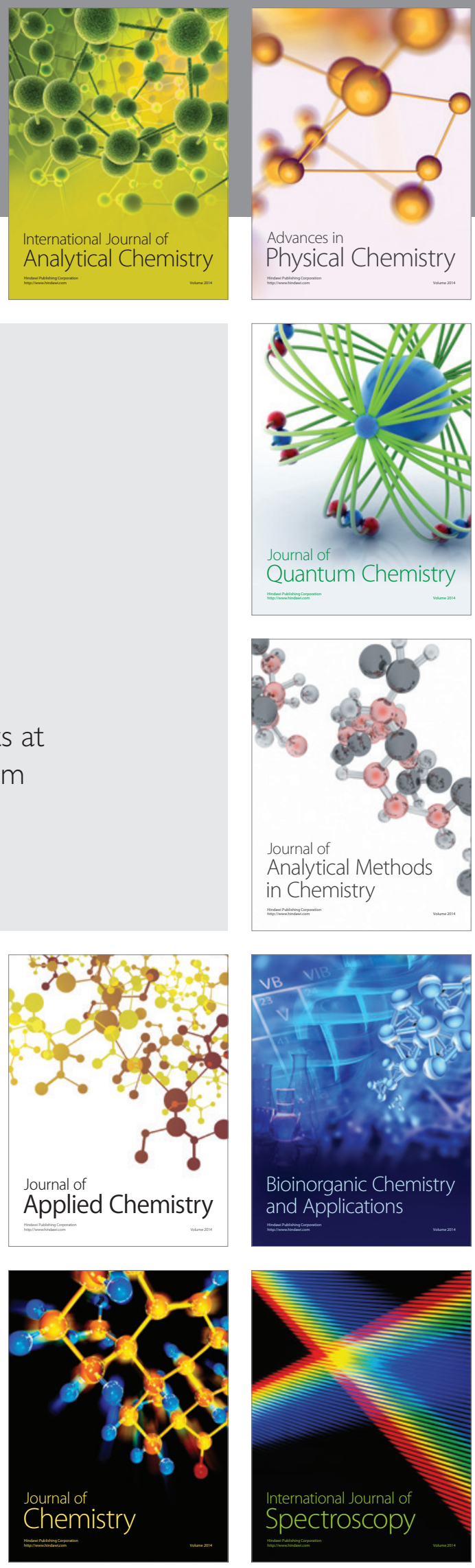